\title{
A propósito de Panamá: \\ La política exterior de Estados Unidos y el "Destino Manifiesto"
}

\author{
On Panamá: \\ United States Foreign Policy and the Manifest Destiny
}

Adolfo León Atehortúa Cruz*

Resumen

Cuatro temas son el propósito del presente escrito: las concepciones más importantes sobre la política exterior norteamericana,la expansión de la frontera estadounidense a lo largo del siglo XIX, el pensamiento de Bolívar con respecto al istmo y el avance de Estados Unidos por Centroamérica durante la misma centuria. El trasfondo de la observación sobre los hechos gira en torno a la política exterior del gran país del norte y su "destino manifiesto". Su objetivo, era comprender lo sucedido en 1903: la separación protagonizada por Panamá frente a Colombia.

Palabras claves:

Política exterior, expansión estadounidense, Destino Manifiesto, Panamá, Bolívar, Jefferson.

\section{Abstract}

Four topics are the purpose of this paper: the most important conceptions on the North American foreign policy, the expansion of the American frontier along the XIX century, the thought that Bolivar expressed on Panama, and the advance of the United States in Central America during the same century. The observation will focus on the United States' foreign policy, in order to understand the separation of Panama in 1903.

Keywords:

Foreign policy, United States' expansion, Manifest Destiny, Panama, Bolivar, Jefferson.

Artículo recibido el 16 de febrero de 2007 y aprobado el 30 de abril de 2007

* Profesor titular del Departamento de Ciencias Sociales, Universidad Pedagógica Nacional. adolfoatehortua@cable.net.co. 


\section{Presentación}

Hace poco más de un siglo, el territorio que comprende hoy Panamá dejó de ser colombiano. El istmo figuró en el mapa de Colombia desde 1821 hasta 1903, año en que, a instancias de Estados Unidos, Panamá se declaró república independiente.

Con motivo de dicho centenario, una caudalosa bibliografía revivió los instantes de la separación de acuerdos con diversos puntos de vista: desde la celebración por la independencia, hasta el lamento y reclamo frente al "robo" norteamericano. Sin embargo, en gran parte de los estudios realizados se habló poco de tres aspectos históricos y vitales para comprender lo sucedido con respecto a Panamá. Se trata de la expansión alcanzada por la frontera estadounidense a partir de su propia independencia, de la relación Panamá-Colombia en vida de Bolívar y, finalmente, de la manera como Estados Unidos comenzó a extender su imperio a través de Centroamérica.

En este artículo se intentarán abordar tales temas desde la óptica de la política exterior estadounidense, del pensamiento de Bolívar y de la realidad final del "destino manifiesto" sobre el canal de Panamá, respectivamente.

\section{La expansión frente al aislacionismo y la intervención como filosofías de política exterior}

Poco tiempo después de alcanzar la independencia, sus más ilustres presidentes fijaron el derrotero de la política exterior de la Unión Americana. Nos referiremos en concreto a dos: George Washington y Thomas Jefferson.

En una carta que ha sido calificada como testamento político de George Washington, "Adiós al pueblo americano", la doctrina consistía en "no tomar nunca partido en las querellas internas de Europa"; en "aprovechar el aislamiento y lejanía" para "formar una nación regida por un gobierno fuerte, que no tenga que temer nada de nadie", y en estar en posición de "escoger entre la paz y la guerra sin más guía que nuestras acciones, nuestro interés y la justicia"1.

Para sostener la paz con Europa, Estados Unidos se comprometía a evitar cualquier interferencia o intervención en los asuntos del viejo continente. Su objetivo era dedicar la diplomacia y todo esfuerzo del naciente país a consolidar su Estado federal y a mantener la paz con las potencias europeas, alejándose de sus disputas.

Aunque para algunos autores esta doctrina de los "dos hemisferios" es prudente y estratégica, los analistas de la política exterior norteamericana han definido dicha línea de pensamiento como "aislacionismo"2.

$\mathrm{Al}$ momento de su génesis, Estados Unidos se consideraba un país relativamente débil, agrario y poco desarrollado; su ciudad más grande estaba lejos de igualar las dimensiones de México o La Habana; su balanza de pagos era desigual frente a la imperiosa importación de los bienes no producidos en su propio territorio, y su geografía no alcanzaba siquiera la décima parte de lo que llegó a ser un siglo después. En estas condiciones, las buenas relaciones con el exterior y la consolidación de la Unión, la neutralidad y el aislacionismo, les parecían las políticas más aconsejables a un importante sector del Partido Republicano, a John Adams y a la facción federalista de Alexander Hamilton, las políticas más aconsejables.

Más allá de la discusión sobre el aislacionismo relativo o absoluto de George Washington, en la doctrina se recomendaba evitar un odio o apego habitual a otros países y "mantenerse libres de alianzas permanentes con cualquier porción del mundo exterior", sin descartar las “alianzas temporales para emergencias extraordinarias". Al mismo tiempo, Washington lamentaba los "efectos funestos" del regionalismo y del partidismo, sin desconocer la

1 Citado por Alexis de Tocqueville, 1980). La democracia en América, Vol. 1. Madrid: Alianza Editorial. p. 214.

2 Thomas Bailey, (1959). A diplomatic history of the American people. New York: New York University Press. 
importancia de los partidos "para el control de la administración" y para "mantener vivo el espíritu de libertad". Según el criterio de los fundadores de esa nación, la mejor forma en que Estados Unidos podía servir a sus valores era perfeccionando la democracia en el interior para actuar como guía frente a los demás pueblos de la humanidad. Si bien esta declaración pudo no tener en el momento la resonancia que se le atribuye, sirvió en el futuro para guiar la política exterior estadounidense.

En la segunda línea de pensamiento, a diferencia de Washington, se planteaba la intervención y el compromiso. En el Partido Republicano-Demócrata, dirigido por Thomas Jefferson, una tendencia proponía la alianza con la Francia revolucionaria en su lucha contra Inglaterra y las históricas monarquías europeas. Su concepción persiste hasta el presente. Los valores de la nación, en cuanto ejemplo de virtud y pureza, le imponen a Estados Unidos la obligación de actuar como "cruzado" ante el mundo. La convicción de un destino trazado por Dios, al igual que la fe en un país que representa los valores más preciados de la democracia, los derechos y la libertad, los impele a buscar y a plantar por doquier todo gobierno a postración y semejanza. Para Estados Unidos, desde el principio de su construcción nacional y hasta el presente, no hay sistema político ni estilo de vida más justos y dignos que los propios.

La primera experiencia de este tipo la vivió el propio Jefferson en Francia. Embajador de Estados Unidos en París, proporcionó a La Fayette y a los revolucionarios la Constitución de Filadelfia, que sirvió de fundamento para los Derechos del Hombre y del Ciudadano. Sin embargo, a pesar de su aparente similitud, existirá una enorme diferencia entre ésta y aquéllos: no fueron móviles democráticos radicales ni propuestas revolucionarias de reforma social los que impulsaron a la élite política, reunida en 1776 en Filadelfia, a manifestarse de ese modo por la soberanía popular; si así hubiere sido, la libertad de los esclavos se habría convertido en una decisión prioritaria. En realidad, lo que la élite buscaba al mencionar el postulado de igualdad entre los hombres y el derecho de los gobernados a destituir los gobernantes que se opusiesen a los intereses del pueblo, definidos como "vida, libertad y felicidad", era justificar la independencia y constitución de un nuevo Estado frente a los ojos de Europa.

Elegido presidente en 1800 con un programa de política exterior favorable al enfrentamiento con Inglaterra, Jefferson decidió actuar con prudencia y evitar alianzas o posturas beligerantes. Representante de un próspero sector agrícola que se expandía paulatinamente hacia el oeste, Jefferson prefirió pensar en la ampliación de la frontera norteamericana.

Para algunos analistas, existía en Jefferson una contradicción, propia de todo su partido: de conformidad con los intereses de los pequeños agricultores del norte, fue demócrata consecuente, opuesto al predominio de los capitalistas de Nueva York, Filadelfia y Nueva Inglaterra, pero al mismo tiempo el sector demócrata sureño, latifundista y esclavista, lo impulsó hacia un expansionismo que parecía contradecir sus ideales de libertad, igualdad y fraternidad humanas 3 .

Con todo, habría que observarlo con mayor integralidad. Jefferson no sólo es redactor de la Declaración de Independencia; es también uno de los más consagrados defensores de la separación de la Iglesia y el Estado, y heredero de los filósofos liberales del siglo XVIII. De noble cuna, se mostró contrario a seguir las más rancias costumbres aristocráticas, se opuso a los establecidos derechos de herencia y primogenitura, y se dedicó a la ciencia. Naturalista, etnólogo, arquitecto, hombre de letras, amigo de las ciencias sociales y fundador de la Universidad de Virginia, debe considerársele, ante todo, un profundo pensador nacionalista, y en estos términos su propuesta de expansión, antes que conservadora, puede calificarse de liberal para los intereses de Estados Unidos4.

El sentido de su concepción puede entenderse mejor si se mira en contraste con las posturas

3 Demetrio Boersner, (1996). Relaciones internacionales de América Latina. Breve historia. Caracas: Nueva Sociedad, p. 49.

4 Una interesante biografía de este prócer estadounidense es la escrita por Claude Fohlen (1992). Thomas Jefferson. París: Presses Universitaires de Nancy. 
asumidas por Hamilton. Este último previó una economía capitalista diversificada y una agricultura equilibrada por el comercio y la industria en un país conservadurista, dirigido por una élite acaudalada y con un gobierno central fuerte. Más soñador y menos profeta, Jefferson temió el desarrollo de ciudades multitudinarias concebidas bajo el deplorable espectáculo de aristocracias capitalistas en suburbios de élite y masas depravadas en arrabables miserables 5 . Propuso además una república descentralizada, en la que predominaran agricultores y granjeros frente al poder de comerciantes y financistas. Enamorado de una esclava con la que tuvo parte de su prole, sugirió redactar un código penal más humano e impulsó la eliminación de la esclavitud, así como la creación de escuelas públicas en Virginia.

La construcción de un nuevo Estado, en medio de concepciones filosóficas diversas, condujo a sus dirigentes a una línea particular de política exterior que logró cierto consenso. El desarrollo de la agricultura y la navegación, sectores fundamentales de la economía estadounidense, impuso los lineamientos del gobierno federal en procura de alcanzar sus grandes objetivos: adquirir territorios dedicados a la producción, ampliar el número de mercados para la exportación y asegurar las rutas comerciales en el Atlántico, así como las vías fluviales al oeste americano, incluyendo el Mississippi. La discusión se saldó, entonces, tras el ideal práctico de la Unión y las necesidades concretas de su floreciente desarrollo.

En ese sentido, el aislacionismo de Estados Unidos fue útil para afianzar su independencia y defender los intereses nacionales. Como ningún país europeo constituía una amenaza seria mientras estuviere enfrentado a sus rivales del viejo mundo, Washington aprovechó con habilidad los conflictos para mantener su independencia y obtener los beneficios más inesperados.

No obstante, al mismo tiempo, el expansionismo de Jefferson iluminó el fuerte desarrollo norteamericano. Desde sus inicios, Estados Unidos buscó

5 George B Tindall y David E. Shi, (1995). Historia de los Estados Unidos, tomo I. Bogotá: Tercer Mundo Editores, p. 188. su expansión en el continente con especial énfasis y dedicación. Antes de 1800, una serie de tratados fijaron los límites con Canadá y la Florida en su favor. Obtuvo de España, enfrentada a Francia, la libertad de navegación por el Mississippi, y de Francia, enfrentada a España, la Luisiana; prácticamente la tercera parte de lo que hoy es Estados Unidos, y que Napoleón vendió confiado en que de esa manera le creaba un rival marítimo a Inglaterra.

\section{El crecimiento de la frontera estadounidense}

Un ejemplo clásico del practicismo estadounidense se encuentra en la compra de Luisiana. Colonizada por los franceses a principios del siglo XVIII, cedida a España tras la derrota en la guerra de los Siete Años y recuperada por Napoleón a cambio de la región de Toscana, en la Italia septentrional, Luisiana significaba no sólo el "destino natural" de los granjeros aledaños al Mississippi, sino también un espacio decisivo para la seguridad nacional.

Jefferson reconocía el peligro que entrañaba para Estados Unidos el contar con una posesión francesa en tierras continentales y vecinas. De hecho, la misma España incomodó a los norteamericanos con el cobro de peaje y la ocupación de Nueva Orleans. Ahora, la poderosa Francia ofrecía una preocupación mucho mayor, con su intención de implantar una zona de influencia que partía de Santo Domingo y amenazaba con crecer en Centroamérica y el Caribe a costa de España.

Así las cosas, Jefferson ofreció entonces a Francia comprarle Nueva Orleans con sus zonas fluviales circundantes, y encargó a Robert Livingston, ministro plenipotenciario en París, y a James Monroe, enviado en misión especial, el trámite del negocio. En caso contrario, Jefferson contemplaba una alianza con Inglaterra como opción para frenar el avance francés en suelo estadounidense.

Si bien el interés norteamericano encontró una negativa radical en Napoleón y Talleyrand, la alternativa de Inglaterra no fue necesaria. En 1803, luego de la derrota del ejército francés en Haití y urgido de medios para su lucha contra Inglaterra, Napoleón ordenó la venta de toda la Luisiana. 
Sin embargo, la dificultad consistía en que, constitucionalmente, el presidente estadounidense no tenía autorización para negociar la compra de territorio alguno. Así mismo, si se tramitaba una enmienda, mucho se temía que Napoleón cambiara de criterio y retirara la oferta. Jefferson, confiando en su poder para hacer tratados, decidió la compra en forma rápida y sin mayores consultas: duplicó el territorio del país y se apoderó de todo el valle sobre el Mississippi.

En adelante, a Estados Unidos no le importó anexar más tierras. Los intereses financieros y comerciales de Nueva Orleans se unieron a los intereses latifundistas de los estados sureños. Sus avances hacia el oeste o hacia el sur, incluso, no se miraron como parte de su política exterior sino como asunto interno y orden natural de las cosas.

Osado y visionario, Thomas Jefferson tuvo siempre claro cuál era la dirección del "Destino Manifiesto”. En 1809, cuando José Bonaparte, el hermano mayor del emperador Napoleón, accedía al trono de España, no vaciló en plantear a los franceses una negociación que permitiera a Estados Unidos apropiarse de la península de la Florida y la isla de Cuba, a cambio de neutralidad en la lucha por la independencia que libraban México y las demás provincias hispanas. En criterio de Jefferson, "lo único que en ese caso nos faltaría para completar el imperio más vasto que jamás se vio en el mundo sería incluir en nuestra confederación el país que tenemos al norte"."Estoy convencido -escribió con orgullo- de que nunca ha habido una Constitución tan bien calculada como la nuestra para poner en armonía un extenso imperio con el principio del gobierno propio"6.

Muy temprano, en 1810, Estados Unidos patrocinó, durante la presidencia de Madison, la primera rebelión en tierra ajena para favorecer sus intereses: los colonos de Baton Rouge proclamaron la República de Florida Occidental y se anexaron de inmediato al gran país vecino.

6 Jefferson's Works, tomo V, p. 443. Citado por José I. Rodríguez, (1900). Anexión de la isla de Cuba a los Estados Unidos de América. La Habana: Imprenta La Propaganda, p. 52.
Con sobrada razón y en forma premonitoria, el ministro de España en Washington, Luis de Onís, identificó los verdaderos objetivos de Estados Unidos. En carta dirigida en 1812 al virrey de México, expresaba el diplomático:

Cada día se desarrollan más y más las ideas ambiciosas de esta República... Este gobierno se ha propuesto nada menos que fijar sus límites en la embocadura del río Norte o Bravo, siguiendo su curso hasta el grado 30, y de allí, tirando una línea recta hasta el Pacífico, tomando por consiguiente las provincias de Texas, Nuevo Santander, Coahuila, Nuevo México y parte de las provincias de Nueva Vizcaya y de la Sonora. Parecerá este proyecto un delirio a toda persona sensata: pero no es menos seguro que el proyecto existe, que se ha levantado expresamente un plano de dichas provincias por orden del gobierno, incluyendo también en dichos límites la Isla de Cuba como una parte natural de la República?.

En efecto, el avance norteamericano prosiguió sobre el resto del territorio de Florida. En 1813, una porción adicional de territorio fue oficialmente acogida por el Congreso de la Unión y en 1818 John Quincy Adams propuso a España la compra de toda la Florida.

El propio Monroe, elegido presidente, justificó aún más la expansión por el oeste como una necesidad estadounidense para convertirse en gran potencia:

Debe quedar claro para todos que cuanto más avance la expansión, mayor será la libertad de acción, más perfecta su seguridad y, en todos los otros aspectos, mejor será su efecto sobre todo el pueblo norteamericano. La extensión del territorio, sea grande o pequeño, da a una nación muchas de sus características. Indica el grado de sus recursos, de su población, de su fuerza física. En suma, marca la diferencia entre una potencia grande y otra pequeñå.

7 lbíd., p. 54.

8 James Monroe. "La Doctrina”. Citado por Eduardo Prado (1973). Antología Latinoamericana del siglo XX. Lecturas Universitarias, 19. México: Unam. 
En conclusión, los dirigentes estadounidenses no tomaron el lineamiento de Washington como un juicio geopolítico práctico, sino como una máxima moral. Sintiéndose depositarios de la razón y de la libertad, estimaron natural interpretar la seguridad que les conferían los dos grandes océanos como señal y "obsequio de la Divina Providencia".

No obstante, Jefferson fue más allá. En cartas remitidas al entonces presidente Monroe en junio y octubre de 1823, expresa su preocupación no sólo por el norte de México y la isla de Cuba; A partir de ésta y de la Florida, el proyecto de expansión registra por primera vez el interés norteamericano por Panamá y el istmo entero. Al ser consultado por Monroe acerca de cuál debería ser la política de la Unión frente a los planes de la Santa Alianza de ayudar a Fernando VII en la reconquista de sus antiguas colonias americanas, advirtió textualmente:

Nuestra máxima primera y fundamental debiera ser la de jamás intervenir en las disputas de Europa, y la segunda, no consentir que Europa intervenga en los negocios cisatlánticos. Pero tenemos, desde luego, una cuestión que plantearnos: ¿anhelamos adquirir, para nuestra propia confederación, una o más provincias españolas? Yo confieso, con toda sinceridad, que siempre consideré a Cuba como la anexión más interesante que pudiera jamás hacerse a nuestro sistema de estados... la dominación que Cuba, en unión de la punta de la Florida, podría darnos sobre el golfo de México y los países y el istmo bañados por sus aguas, llenaría la medida de nuestra seguridad y bienestar político ${ }^{9}$.

Las cartas de Jefferson, sin lugar a dudas, se convirtieron en pieza fundamental de la Doctrina Monroe, "América para los americanos", presentada el 2 de diciembre del mismo 1823. El pretexto era el peligro inexistente de un avance ruso por Alaska, pero la realidad se escondía tras la mirada expansionista de Estados Unidos sobre México, Centroamérica y el Caribe, expresada con decisión

9 Th. Barclay. La doctrina de Monroe et la Venezuela. Revue de Droit International et de Législation Comprarée, t. XXVIII, p. 511. Citado por Isidro Fabela, (1920). Los Estados Unidos contra la libertad. Barcelona: Talleres Gráficos Lux, p. 21. y transparencia en el citado cruce epistolario de los líderes del país del norte.

En los tres años siguientes, la política de Estados Unidos en relación con Cuba y el Caribe fue más contundente. El presidente John Quincy Adams, antiguo secretario de Estado de Monroe, exigió a España el compromiso de no vender, por ningún motivo, las islas de Cuba y Puerto Rico a potencias europeas. A cambio de esto Estados Unidos se comprometió, una vez más a "no permitir ni auxiliar plan alguno que tienda, por medio de expediciones, armamentos o cualquier otra cosa, a fomentar discordias intestinas en las mencionadas islas, perturbar su tranquilidad o intentar su separación del imperio español"10. El "Destino Manifiesto" le auguraba a Estados Unidos una expansión geográfica sobre Centroamérica y el Caribe, para la cual era preciso esperar el momento oportuno.

\section{La "Patria Grande" de Bolívar y el Congreso Anfictiónico de Panamá}

Los compromisos con España alimentaron las decisiones y actitudes de Estados Unidos frente al llamado Congreso Anfictiónico de Panamá. La venta de la Florida, por parte de España, se realizó con dos condiciones: Estados Unidos renunciaría a toda reclamación sobre el territorio de Texas y se comprometería a no reconocer la independencia de los países hispanoamericanos.

La idea de una "Patria Grande", desde México hasta la Patagonia, la expresó inicialmente Simón Bolívar el 15 de septiembre de 1810 en el Morning Chronicle de Londres, cuando presentaba ante Inglaterra los pliegos diplomáticos de los sucesos venezolanos frente al gobierno de España. A juicio del Libertador, se acercaba el momento ideal para que todos los pueblos de la América sometida se alzaran con miras a conquistar su independencia $y$, seguidamente, se unieran en una poderosa confederación 11.

10 Citado por José I. Rodríguez. Op. cit., p. 64.

11 Cf. Miguel Acosta Saignes (1983). Bolívar. Acción y utopía del hombre de las dificultades. Caracas: Universidad Central de Venezuela. 
Como constante a lo largo de su vida política y guerrera, la idea prosiguió en la "Memoria de Cartagena”, en su epistolario, en sus intervenciones ante el Congreso de la Nueva Granada y en su "Campaña Admirable". No obstante, apareció con nitidez en la "Carta de Jamaica":

Es una idea grandiosa pretender formar de todo el Nuevo Mundo una sola nación con un solo vínculo, que ligue sus partes entre sí y con el todo. Ya que tiene un origen, una lengua, unas costumbres y una religión, debería, por consiguiente, tener un solo gobierno que confederase a los diferentes estados que hayan de formarse. ¡Qué bello sería que el istmo de Panamá fuese para nosotros lo que el de Corinto para los griegos!"12.

De Boyacá hasta Ayacucho, Bolívar no olvidó nunca su objetivo. En 1822, cuando avanzaba desde la Nueva Granada hacía el campo de batalla en Pichincha, renovó su meta:

El gran día de la América no ha llegado. Hemos expulsado a nuestros opresores, mas todavía nos falta poner el fundamento del pacto social que debe formar de este mundo una nación de repúblicas. La asociación de los cinco grandes estados de América es tan sublime en sí misma, que no dudo vendrá a ser motivo de asombro para Europa. ¿Quién resistirá a la América reunida de corazón, sumisa a una ley y guiada por la antorcha de la libertad?13.

Los cinco estados eran México, Perú, Chile, Buenos Aires y Colombia. Y así el Libertador comenzó a buscar su objetivo, procurando uniones parciales. Muy temprano, en 1818 y desde Angostura, había propuesto su idea por escrito a los patriotas de Argentina, la cual sólo empezó a concretarse en julio de 1822, cuando se firmó el primer pacto de unidad entre Perú y Colombia y cuando, un año después, se suscribió un tratado de amistad y alianza con Chile y Argentina.

12 Simón Bolívar, (1947). Obras completas. Vol. I. Compilación y notas de Vicente Lecuna. La Habana: Lex, p. 171.

13 Ibíd. (1822). Cartas del Libertador. Recopilación de Vicente Lecuna. Cali: varias ediciones.
Con mayor claridad, en octubre de 1823, Bolívar logró un tratado de unión, liga y confederación perpetua entre México y Colombia en el que se incluyó una cláusula sobre la defensa de la integridad territorial de ambos países. Igualmente, con la América Central, separada de México después de la caída de Iturbide, en 1825, Colombia firmó un nuevo tratado de unidad y confederación que sentó las bases para convocar al Congreso de Unidad Americana en Panamá.

De inmediato, Bolívar promovió el encuentro; en Perú, entregó a los representantes de ese país instrucciones precisas para impulsar una expedición conjunta que liberara al Caribe de la dominación española, al tiempo que persuadió a los representantes de la Nueva Granada para que brindaran su apoyo en tal sentido.

Santander, desde Bogotá, no comprendió el propósito del encuentro citado por Bolívar. Además de las antiguas colonias hispanas e inspirado en una interpretación ingenua de la Doctrina Monroe, Santander decidió invitar a Estados Unidos sin consultarlo previamente con el Libertador.

La correspondencia al respecto entre los dos próceres fue importante. Bolívar advirtió que los norteamericanos, al igual que los ingleses, serían "aliados eventuales y muy egoístas". Santander explicó que había creído conveniente invitar a Estados Unidos porque, con seguridad, los aliados con Colombia "se alegrarían de tener por compañeros a tan ilustres asistentes”. Bolívar le recomendó, entonces, consultar primero al congreso e insistió en que "los americanos serán los mayores opositores al título de la independencia y la libertad; pero el verdadero título es por egoísmo y porque nada temen en su estado doméstico"14. Aunque Bolívar insistió una vez más en que "los americanos no deben entrar al congreso del istmo", ya era tarde. Al igual que Santander, el presidente de México había cursado invitación a Estados Unidos y Washington había nombrado a sus representantes.

14 Versión epistolar citada por Saignes Miguel Acosta. Bolívar. Acción y utopía del hombre de las dificultades. Op. cit. 
Casualmente, en las instrucciones generales que los plenipotenciarios norteamericanos recibieron de su presidente Adams se mencionó por primera vez el interés concreto con respecto a Panamá y la construcción de un canal sobre su suelo. En opinión de Estados Unidos, una expedición sobre Cuba era inaceptable; Cuba no podía gobernarse a sí misma, entregarse a otra potencia, ni anexarse a México o a la Nueva Granada. Pero, sobre todo, en los pliegos se advertía "la importancia que tendrá Cuba cuando se abra una ruta interoceánica a través del istmo", razón por la cual "la obra de Cuba y del canal se han de hacer no por esta u otra nación, sino por todas en conjunto". Finalmente, pedía a sus dignatarios realizar el "mayor esfuerzo posible para inducir a suspender la ejecución de sus proyectos".

Ante la comisión de negocios extranjeros de la Cámara de Representantes de Estados Unidos, el presidente fue más explícito para obtener la aprobación de la delegación norteamericana en el congreso celebrado en Panamá:

La condición de las islas de Cuba y Puerto Rico es un asunto de profundo interés, que influye directamente sobre los intereses presentes y futuros de nuestra Unión... La invasión de ambas islas por fuerzas combinadas de México y Colombia es, según se confiesa, uno de los objetos que habrá de tratarse en Panamá. Los resultados a que esto pueda conducir en vista de la composición peculiar de la población de aquellas islas y el peligro posible, de que al fin y al cabo vengan a caer éstas en manos de una nación de Europa, que no sea España, no permiten mirar con indiferencia lo que se delibere en Panamá, o las consecuencias que de ello podrán derivarse... La totalidad de nuestros esfuerzos habrá de encaminarse en el sentido de conservar el estado actual de las cosas, la tranquilidad de las dos islas a través de la paz y la seguridad de sus habitantes ${ }^{15}$.

En efecto, Estados Unidos temía un levantamiento de los esclavos negros a favor de la causa emancipadora, que pudiera imbuir de libertad a sus esclavos sureños. Pero, ante todo, prefería a Cuba y

15 Cf. José I. Rodríguez. Op. cit. pp. 83-84.
Puerto Rico en manos españolas a que estuvieron en poder de Inglaterra o en alianza con sus hermanos centro y suramericanos. A España, finalmente, podría comprárselas, como ocurriría con la Florida, o podría arrebatárselas en guerra, como hizo para conseguir con Puerto Rico, Cuba y Filipinas.

Por esto, su sabotaje al Congreso Anfictiónico se expresó abiertamente. Tanto Estados Unidos como Inglaterra influyeron ante las Provincias Unidas del Río de la Plata para que no asistieran. Chile envió tarde a sus embajadores y los norteamericanos se instalaron también a última hora en México y Colombia, para solicitar la continuación de las sesiones en un lugar distinto de Panamá. Aprobado el traslado del congreso a Tacubaya (México), por motivos de salubridad, el secretario de Estado de Estados Unidos manifestó su compromiso de respaldar el reconocimiento de las repúblicas americanas por España y de solicitar el apoyo de la Rusia zarista en tal sentido, a cambio de no tocar las Islas. Finalmente, se presionó al presidente de México para que expresara su rechazo a cualquier ambición sobre las islas, negara su participación en una expedición libertadora y suspendiera en forma definitiva la nueva convocatoria del congreso.

La idea bolivariana de la "Patria Grande" y de liberar a Cuba y Puerto Rico de la dominación hispana, murió en manos de la Doctrina Monroe. Si bien Bolívar intentó renovar sus propósitos tras regresar a la Nueva Granada, las condiciones que encontró le impidieron incluso permanecer en el poder y mantener, en últimas la unidad colombiana con Perú, Venezuela y Ecuador.

Hasta Monroe, la línea fundamental de Estados Unidos había sido no inmiscuirse en los conflictos europeos. Ahora, con la doctrina, se negaba a Europa la posibilidad de inmiscuirse en los asuntos norteamericanos. Pero, en el fondo, la idea de Monroe de lo que constituían tales asuntos, como lo reconoce Kissinger, era realmente expansiva ${ }^{16}$. Se declaraban en libertad para extenderse por todo el continente al amparo de una "pureza" inspirada, como lo presagió Bolívar, en nombre de la libertad:

16 Henry Kissinger (1995). La diplomacia. México: FCE, pp. 27 a 32 
Los Estados Unidos parecen destinados por la Divina Providencia para plagar la América de hambre y miseria en nombre de la libertad.

A lo largo del siglo XIX, la orientación principal de la política exterior norteamericana se basó, entonces, en extender la aplicación de la Doctrina Monroe como corolario del "Destino Manifiesto".

\section{El oeste americano deambula por Centroamérica}

A pesar de que en 1817, para obtener la Florida, Estados Unidos renunció a toda aspiración sobre Texas en virtud de la ley de neutralidad que firmó con España, pocos años después de la Doctrina Monroe, decidió ensayar, por segunda vez, la táctica que emplearían en forma refinada sus aliados panameños en 1903.

En efecto, en 1836, con el pretexto de atacar el excesivo centralismo de ciudad de México, estalló en Texas un motín que contó con recursos extraordinarios aportados por Estados Unidos; como resultado de la insurrección, se detuvo en San Jacinto al presidente Santa Anna, quien para recuperar su libertad, concedió entonces la autonomía a Texas y dispuso el retiro total del ejército mexicano.

Reconocida de inmediato por Estados Unidos, la "nueva república" solicitó formalmente su anexión en 1845. La oposición mexicana, valerosa y fuerte, no pudo vencer al ejército estadounidense que cañoneó Veracruz y avanzó sobre la capital. Santa Anna capituló entonces y entregó a Estados Unidos en el Tratado de Guadalupe Hidalgo (1848), no sólo a Texas, sino también a California, Nuevo México y todas las provincias anunciadas 40 años antes por Don Luis de Onís.

El hallazgo del oro californiano, en medio de la guerra, terminó por transformar definitivamente el mapa norteamericano. La economía metropolitana de las grandes ciudades en la costa este necesitó acercarse al oro del oeste por una ruta rápida y segura. La navegación de vapor buscó el paso de un océano a otro y redescubrió en Panamá el viejo tránsito que seguían las mercancías destinadas a las tierras españolas en el mar del Sur. Muy tem- prano, en 1849, el gobernador de California estuvo dispuesto a levantar en Panamá fortificaciones que garantizaran y protegieran el paso norteamericano por el istmo; poco después, consiguió el consulado permanente en Colón y obtuvo por último la firma del Tratado Mallarino-Bidlack para construir el ferrocarril transoceánico.

Las condiciones fueron leoninas. El artículo sexto del tratado, por ejemplo, garantizó a la compañía constructora del ferrocarril el monopolio exclusivo de su medio de transporte, en tanto que el artículo 35 posibilitó la intervención militar de Estados Unidos para asegurar la soberanía y la propiedad del istmo.

En realidad, ya estaban garantizadas. Ulises Grant, general de generales en la guerra de Secesión, advirtió que la frontera norteamericana hacia el sur llegaba a Panamá: Estados Unidos tenía la necesidad de construir un canal, pero éste sólo podría hacerse por americanos en territorio americano.

El oro californiano, por otra parte, trajo consigo la presencia de millares de aventureros, piratas y filibusteros de nuevo tipo, que empezaron a vagar por Centroamérica al amparo de la ley del más fuerte. William Walker será quizás el clásico representante de estas hordas que llegarán a Panamá en 1856, con la "Guerra de la Sandía". Armado de revólver, un norteamericano asesina a un niño panameño por el delito de ser negro y venderle una sandía cuando quería un melón. El episodio es desastroso y termina con un enfrentamiento general entre nativos y extranjeros. Estados Unidos desembarcó por primera vez en $\mathrm{Pa}$ namá a dos centenares de marines y exigir una fuerte indemnización al gobierno colombiano, que se pagó después con un significativo monto pecuniario.

En adelante, el desembarco de tropas estadounidenses en Panamá, como sucedía en toda Centroamérica, se convirtió en una constante. Las guerras civiles y la presunta necesidad de "proteger las inversiones norteamericanas" fueron el pretexto preferido. En otras ocasiones, el propio gobierno colombiano pidió la colaboración de tales tropas americanas para aplastar insurrecciones nativas, o éstas decidieron intervenir por voluntad propia para sostener gobiernos aliados. Una y otra vez, 
militares estadounidenses transitaron por el istmo con el pretexto de garantizar seguridad a viajeros, equipajes y mercancías. Pero, por el contrario, una y otra vez obligaron al ejército colombiano a transitar desarmado o le negaron la posibilidad de conducirlo por el ferrocarril de un lugar a otro. Los barcos norteamericanos se instalaron en no pocas oportunidades con sus cañones apuntando a las ciudades panameñas. Se negaron a obedecer las disposiciones locales que cerraban el tránsito por Panamá para proteger a su población de epidemias o que exigían el pago de tributos. Desatendieron la ley y se negaron a pagar impuestos. Finalmente, durante la guerra de los Mil Días, los norteamericanos implantaron en Panamá la pena de muerte, que no existía en la legislación colombiana.

Antes de culminar el siglo XIX, Theodore Roosevelt dio un enorme viraje a la política exterior de su país. Con el concepto de "interés nacional", Ro-

\section{Bibliografía}

Acosta, Miguel (1983). Bolívar. Acción y utopía del hombre de las dificultades. Caracas: Universidad Central de Venezuela.

Atehortúa, Adolfo (1994). Estado y Fuerzas Armadas en Colombia. Bogotá: Tercer Mundo, Editores-Universidad Javeriana.

Bailey, Thomas (1959). A diplomatic history of the American people. New York: New York University Press.

Bergquist, Charles (1981). Café y conflicto en Colombia, 1886-1910. Medellín: Faes.

Boersner, Demetrio (1996). Relaciones internacionales de América Latina. Breve historia. Caracas: Nueva Sociedad.

Bolívar, Simón (1947). Obras completas. Compilación y notas de Vicente Lecuna. La Habana: Lex.

Bushnell, David (1984). Eduardo Santos y la Política del Buen Vecino. Bogotá: El Áncora Editores.

De Tocqueville, Alexis (1980). La democracia en América. Madrid: Alianza Editorial.

Deas, Malcolm (1983). La Regeneración y la guerra de los Mil Días, en Aspectos polémicos de la historia colombiana del siglo XIX. Bogotá: Fondo Cultural Cafetero.

Drekonja, Gerhard (1982). Colombia: política exterior. Bogotá: Universidad de los Andes. osevelt insistió en que era deber de Estados Unidos hacer sentir globalmente su influencia y relacionarse con el mundo, so pretexto de mantener su bienestar, seguridad y poderío. Al igual que Washington y Jefferson, Roosevelt creía en el "Destino Manifiesto" y en la supuesta tarea que la Divina Providencia había encomendado a Estados Unidos para plantar en el mundo el reino de la democracia y la igualdad. Pero, en contraste con Washington, sostuvo que la nación del norte tenía un auténtico interés en la política exterior que iba mucho más allá del aislacionismo. Para Roosevelt, Estados Unidos era ya una potencia como cualquier otra y no una singular encarnación de la virtud y la pureza. Si sus intereses chocaban con los de otros países, Estados Unidos tenía la obligación de usar la astucia y la fuerza. Más aún si, en medio de su discurso providencial y mesiánico, las otras naciones no eran más que "bandidos" e "indios". Por eso, ¡decidió tomarse a Panamá! \.

Fabela, Isidro (1920). Los Estados Unidos contra la libertad. Barcelona: Talleres Gráficos Lux.

Fohlen, Claude (1992). Thomas Jefferson. Paris: Presses Universitaires de Nancy.

García, Antonio (1979). El proceso histórico latinoamericano. México: Editorial Nuestro Tiempo.

Kissinger, Henry (1995). La diplomacia. México: Fondo de Cultura Económica.

Leal, Francisco (1984). Estado y política en Colombia. Bogotá: Siglo XXI Editores-Cerec.

Lee Fluharty, Vernon (1981). La danza de los millones. Régimen militar y revolución social en Colombia (1930-1956). Bogotá: El Áncora Editores.

Masur, Gerhard (1948). Simón Bolívar. Albuquerque: Universidad de Nuevo México.

Pécaut, Daniel (1987). Orden y violencia. 1930-1954. Bogotá: Siglo XXI Editores.

Pardo, Eduardo (1973). Antología latinoamericana del siglo XX. Lecturas Universitarias, No. 19. México: Unam.

Rodríguez, José I. (1900). Anexión de la isla de Cuba a los Estados Unidos de América. La Habana: Imprenta La Propaganda.

Tindall, George y Shi, David (1995). Historia de los Estados Unidos. Bogotá: Tercer Mundo Editores. 